\title{
A retrospective cohort study to find out the association of hydroxychloroquine prophylaxis and COVID 19 infection prevention among health care workers in a tertiary care hospital of New Delhi
}

Neeraj Narayan Mathur ${ }^{1}$, Shweta Arora ${ }^{2}$, Sanjeev Kumar Rasania ${ }^{3}$, Manoj Bharatlal Jais ${ }^{4}$, Tanmaya Talukdar ${ }^{5}$

${ }^{1}$ Addl. DG \& Ex Director, Professor of Excellence, ENT Department, Lady Hardinge Medical College, New Delhi 110001; ${ }^{2}$ ExSenior Resident, Community Medicine Department, Lady Hardinge Medical College, New Delhi 110001; ${ }^{3}$ Director Professor \& Head, Community Medicine Department, Lady Hardinge Medical College, New Delhi 110001; ${ }^{4}$ Professor, Microbiology Department, Lady Hardinge Medical College, New Delhi 110001; ${ }^{5}$ Professor, Respiratory Medicine Department, Lady Hardinge Medical College, New Delhi 110001

\begin{tabular}{|c|c|c|c|c|c|c|c|c|}
\hline Abstract & Introduction & Methodology & Results & Conclusion & References & Citation & \multicolumn{2}{|c|}{ Tables / Figures } \\
\hline \multicolumn{9}{|c|}{ ing Author } \\
\hline \multicolumn{8}{|c|}{$\begin{array}{l}\text { Dr. S.K. Rasania, Director Professor \& Head, Community Medicine Department, Lady Hardinge Medical } \\
\text { College, New Delhi } 110001 \text {, } \\
\text { E Mail ID: skrasania@gmail.com }\end{array}$} & 口ing \\
\hline
\end{tabular}

\section{Citation}

Mathur NN, Arora S, Rasania SK, Jais MB, Talukdar T. A retrospective cohort study to find out the association of hydroxychloroquine prophylaxis and COVID 19 infection prevention among health care workers in a tertiary care hospital of New Delhi. Indian J Comm Health. 2021;33(2):250-255. https://doi.org/10.47203/IJCH.2021.v33i02.005

Source of Funding: Nil Conflict of Interest: None declared

\section{Article Cycle}

Received: 14/05/2021; Revision: 10/06/2021; Accepted: 19/06/2021; Published: 30/06/2021 This work is licensed under a Creative Commons Attribution 4.0 International License.

\section{Abstract}

Background- With the high morbidity and mortality year 2020 will be remembered as Covid19 pandemic year. Occupational exposure to COVID 19 among health care workers poses a major risk to their lives. Hydroxychloroquine (HCQ) prophylaxis has been indicated for their use without much scientific evidence. Objective- to find if HCQ prophylaxis had association with COVID19 infection prevention among health care workers. Material \&Method- A retrospective cohort study was conducted; through online by utilizing social media platform, among Health care workers of a tertiary care hospital from 1st June 2020 to 27 July 2020. Those HCWs who have taken HCQ (exposed) and who have not taken (nonexposed) and PCR tested COVID19 Positive were taken as diseased. Results Out of 527 who were analyzed, study subjects who took HCQ prophylaxis had $30 \%$ less chance of having COVID19 test positive, \{RR-0.709(0.383-1.296)\} as compared those who didn't took it, but the results were not significant. Conclusion- Hydroxychloroquine prophylaxis does not prevent Covid 19 infection and more evidence may be required for use of HCQ prophylaxis for COVID19 infection.

\section{Keywords}

Hydroxychloroquine Prophylaxis; Covid-19 Infection; Health Care Workers; Retrospective Cohort Study

\section{Introduction}

Pandemics have not been new to the human history. Spanish Flu of the year 1918, took almost 50 million lives worldwide.(1) But no one could believe that the history will repeat with COVID19. SARS -CoV2 aka COVID19 which has already infected more than 27 million people and caused around 0.8 million deaths worldwide and almost 4.4 million cases and around seventy-five thousand deaths in India \& till now.(2)

With such high transmission rate RO $=3$,(3) globally the country leaders are emphasizing on preventing COVID19 infection either through social distancing, wearing mask or lockdown measures. And one of the solutions for saving our frontline workers is by giving them hydroxychloroquine (HCQ) prophylaxis.

Hydroxychloroquine has been used for the treatment of malaria since 1955 and is also approved for the treatment of rheumatoid arthritis and lupus. Currently, the potential mechanism of action for hydroxychloroquine's effect on SARS-CoV1 and SARS-CoV2 is not fully known. It is hypothesized that increase in endosomal $\mathrm{pH}$ may inhibit viral fusion and replication with interference in ACE2 receptor glycosylation or Sigma-1 receptor.(4)

The Indian Council of Medical Research (ICMR), under the Ministry of Health and Family Welfare, recommended chemoprophylaxis with hydroxychloroquine $(400 \mathrm{mg}$ 
twice on day 1 and $400 \mathrm{mg}$ once a week thereafter for a total 8 weeks) for asymptomatic health- care workers treating patients with suspected or confirmed COVID19, and for asymptomatic household contacts of confirmed cases.(5) Later this advisory was revised and ICMR recommended HCQ prophylaxis to be continued beyond 8 weeks also.(6) Given these side effects using the drug for prophylaxis or treatment is doubtful under the light of clear evidence. Justification: Occupational exposure to COVID 19 among health care workers poses a major risk to their lives. Hydroxychloroquine prophylaxis has been indicated for their use without much scientific evidence.

\section{Aim \& Objective}

To see whether HCQ had association with COVID19 infection prevention among health care workers.

\section{Material \& Methods}

Study Type, Study Population, Study area, Study Duration: Institutional based Retrospective cohort study was done, among the cohort of all Healthcare professionals including Medical Officers, Faculty consultants, Senior and Junior Residents Doctors, interns and nurses, group D staff and administrative staff working in a tertiary care hospital of Delhi during the study period. Data Collection was carried out from 1st June 2020 to 27 July 2020. [Figure 1]

Strategy for collection Indian Council of Medical Research during the last week of March released an advisory stating the guidelines for using HCQ prophylaxis against COVID 19 among health care workers. Following this few of them purchased the drug and later during the 1st week of April HCQ was distributed free of cost to the health care workers by the hospital. Therefore, to find the exposure of HCQ prophylaxis and its compliance among health care workers, those who took the HCQ prophylaxis were taken as exposed and those who did not, were taken as non-exposed which was ascertained by using a semistructured online questionnaire circulated to all the health care workers. A Survey Questionnaire with an inbuilt Participant Information Sheet (PIS) and Consent form (google.doc format) was shared in English and Hindi language and circulated on official emails and authentic social media platforms such as official WhatsApp groups of health care workers. The questionnaire covered the following domains: socio-demographic details of the respondents, history of taking $\mathrm{HCQ}$ prophylaxis and information regarding COVID 19 testing and treatment; which was circulated to all of the above. It was ensured that the link to the survey questionnaire opened only once the participant submitted his/her agreement to (PIS) and consent. A digital copy of the consent form was retained with the PI for purpose of documentation. The confidentiality and anonymity of the data was strictly maintained.

Inclusion Criteria, Exclusion Criteria And those who were already taking HCQ due to some other disease like rheumatoid arthritis before March 2020, or with any previous history of adverse reaction or allergy to $\mathrm{HCQ}$ were excluded from the study.

Sample Size calculation A total of 569 participants submitted the questionnaire online, but 527 study subjects were included as a part of the study as 11 did not gave the consent, 21 were not working in this hospital and 10 participants were already taking HCQ due to some other medical condition thus were excluded.

Working Definition Diseased were defined as those who were tested positive on Real Time - PCR (RT-PCR) for COVID 19 which was done after the last week of March till 27 July 2020 (after HCQ prophylaxis was started by the study subjects) time frame of our study. Covid areaincluded Covid screening center, Flu clinic, Covid ward, Covid OT, COVID Emergency, COVID Care Center, COVID Gynae Casualty and COVID Labour Room; Orange zone wards for suspected cases, Severe acute respiratory tract infection ward (total of 167 beds), where exposure to the Covid suspected or confirmed patients is high. General OPD/ Ward/OT- places in hospital where Non covid patients were seen (moderate exposure). Non Covid area - all the places where patients were not seen (where exposure to the Covid suspected or confirmed patients are low) like college side/administration block. Data Analysis was done using SPSS software version 22.0. Ethical clearance for the study was obtained from the Institutional Ethical Committee. No sampling or any kind of intervention was done.

\section{Results}

Mean age of the study subjects was 35.54 ? 10.82 (2264 years), almost $70 \%$ were female and rest were male. Most common responders were Nurses (27.1\%) and Faculty Consultants (24.7\%). (Table 1) Out of total 305 (57.9\%) study subjects mentioned they were issued HCQ tablet from hospital and $81(15.4 \%)$ purchased from outside, but 229 (43.5\%) consumed the drug. (Table2) Of these 219 (95.6\%) took the tablets as prescribed. 14 study subjects said they were allergic to HCQ. Only 10 (1.9\%) got ECG done before starting HCQ. 38 participants out of 229 reported side effects to HCQ. (not shown in the table). Out of 527 study subjects 281 (53.3\%) refused for testing and $5(0.9 \%)$ had doubtful results, 59(11.2\%) were COVID19 positive and 182 (34.5\%) were COVID19 negative (Table 2). Of total 109 subjects had symptoms suggestive of COVID19 and of those 79 (72.5\%) got tested for COVID19. Of those who were tested positive 12(20.3\%) were admitted in the hospital, rest were isolated only. 24 (10.4\%) participants developed COVID19 symptoms after starting HCQ. Of these 16 (66.6\%) were tested positive for COVID19. (not shown in the table)

Therefore, study subjects who took HCQ prophylaxis had $30 \%$ less chance of having COVID19 test positive, \{RR$0.709(0.383-1.296)\}$ as compared those who didn't took it, but the results were not significant. Also, statistically 
significant association ( $p$ value 0.023 ) was seen with COVID19 test results and HCQ prophylaxis course of the treatment.(Table 3) Those posted in Covid area had the higher chances of having COVID19 as compared to those working in lesser risk zones and association was statistically significant ( $p-0.031)$. (Table 4)

\section{Discussion}

Ours was a retrospective cohort study conducted through online platform by utilizing social media platform like WhatsApp in a tertiary care hospital to find out the association HCQ prophylaxis and COVID19 infection prevention among health care workers. Those study subjects with smart phones were able to access the questionnaire through these social media platforms.

Seventy percent of the study subjects belonged to 21-40 years of the age group. Though, medical demography is increasingly aging in the OECD area (organization for economic cooperation and development area), $38 \%$ of doctors are over 55. In France, the mean age of doctors is 57 years and $41 \%$ of them are over 60.(7) But we had findings just opposite. Nearly $70 \%$ were females $30 \%$ were male study subjects. More number of females in our study could be due to more number of nurse respondents as most of them are females. Also, hospital is attached to Medical College, which serves Medical Graduation and training to only women.

Disease conditions like diabetes, hypertension, respiratory disease have shown to cause higher mortality among COVID19 positive cases. 96 study subjects had one or the other such conditions in our study. Most common were hypertension (38.5\%), followed by diabetes mellitus, respiratory disease and others in the proportion of 22.95, $38.5 \%$, and $16.6 \%$ respectively. More than one condition was also seen among study subjects. Others includedHeart disease (4), Chronic kidney/liver disease (2), Pregnancy (2), Obesity (3), Cancer (1), Multiple disease (4). $\mathrm{BMI}$ was calculated as per weight and height mentioned by the study subjects. But no statistically significant association was noted between COVID19 test results and high risk medical conditions in our study. Only $27.2 \%$ of the study subjects were found to have normal BMI. Rest $3.5 \%$ were underweight, $25.2 \%$ were overweight and $43.7 \%$ belonged to pre-obese and obese categories as per Asian classification of BMI. There was significant difference between BMI among two sexes which could be due to higher proportion of females. (Not shown in the table)

In vitro studies $(8,9,10)$ have shown effectiveness of HCQ against COVID19 infection among different cell lines. But, satisfactory clinical evidence to support this finding is still lacking. Hydroxychloroquine prophylaxis was started by study subjects following the ICMR issued guidelines for the same(5) and was taken by 229 (43.5\%) individuals in our study. Out of total, $57.9 \%$ (305) study subjects mentioned they were issued HCQ tablet from the hospital and 81 (15.4\%) purchased from outside, but only $43.5 \%$ (229) consumed the drug. This may be due lack of trust among the study subjects related to effectiveness of the HCQ for COVID19 infection prevention or fear of side effects related to the drug which stopped them from taking the prophylaxis despite the availability of the drug. Of those who took the drug, 219 (95.6\%) took the tablets as prescribed by ICMR. While a different regimen was followed by Boulware et al (2020) who did a randomized, double-blind, placebo-controlled trial in 821 participants, in their trial within 4 days after exposure, participants were randomly assigned to receive either placebo or hydroxychloroquine ( $800 \mathrm{mg}$ once, followed by $600 \mathrm{mg}$ in 6 to 8 hours, then $600 \mathrm{mg}$ daily for 4 additional days).(11) In our study, 14 study subjects said they are allergic to HCQ and only 10 (1.9\%) got ECG done before starting HCQ. Almost $80 \%$ of the study subjects took HCQ continuously and either never or once skipped the dose. A full course of 8 weeks of HCQ prophylaxis was completed by $54.6 \%$ study subjects while $21.4 \%$ took the partial prophylaxis and $24 \%$ were still taking the drug while the study was carried out. Those who took partial course, discontinued the drug intake either due to some side effects or they had COVID19 positive test results or they were not satisfied with evidence that the drug is effective in prevention of COVID19 as per their online responses. Boulware et al in their study mentioned similar findings as ours where $75.4 \%$ of participants in the hydroxychloroquine group (312 of 414 ) and $82.6 \%$ of those in the placebo group (336 of 407) having taken all 19 prescribed tablets over a period of 5 days $(P=0.01)$.(11) The most common reason that participants stopped taking the assigned hydroxychloroquine or placebo was side effects. In our study, 38 participants out of 229 reported side effects due to HCQ. Common side effects reported were gastritis, nausea, loose stools, headache, metallic taste, redness of eyes and palpitations. Of these only 2 informed pharmacovigilance department. Similar finding was reported by Sun Hee Lee et al (2020) where 32 individuals (15.6\%) reported one or more symptoms during the course of Post exposure prophylaxis with HCQ. The most common symptoms were diarrhoea or loose stool (9\%), skin rash $(4.3 \%)$, gastrointestinal upset $(0.95 \%)$ and bradycardia (0.95\%).(12) Post exposure prophylaxis was discontinued in 5 patients $(2.7 \%)$ due to gastrointestinal upset (2), bradycardia (2) and need for fasting.

RT PCR testing was offered to the study subjects, of total $281(53.3 \%)$ refused to get the test done and out of 246, $11.2 \%$ were tested positive for COVID19. Of those who were tested positive $12(20.3 \%)$ study subjects were sick thus, admitted in the hospital, rest were isolated only. A total of 109 study subjects developed symptoms suggestive of COVID19, but $27.5 \%(30)$ of these did not get the COVID19 test done. Findings were statistically significant $p$ value $<0.01$. This could be due to technique 
the of COVID19 testing through Nasopharyngeal swab which is not acceptable to many.

Out of 59 who were tested positive for COVID19, reasons for getting the test done were as reported by study subjects, $42.3 \%$ got the test done before developing symptoms suggestive of COVID19, another $22 \%$ had a contact with suspected/ confirmed case of COVID19, $13.5 \%$ said they had a contact with a health worker who was tested positive for COVID19, 6.7\% went into area where confirmed cases of COVID19 were present, 1 participant mentioned to have fear of developing COVID19 and another $13.5 \%$ did not gave any reasons. Statistically significant association was established with a p-value $<0.01$.

(22/59: $37.3 \%$ ) of the study subjects who were tested positive for COVID19 had taken HCQ as prophylaxis and study subjects who took HCQ prophylaxis had $30 \%$ less chance of having COVID19 test positive, \{RR- 0.709(0.3831.296)\} as compared those who didn't took it. While the association of HCQ prophylaxis intake and COVID19 infection was statistically not significant ( $p$ value-0.263). Our study findings were similar to those reported by Boulware DR et al (2020) who found the incidence of new illness compatible with COVID19 did not differ significantly between participants receiving hydroxychloroquine (49 of 414 [11.8\%]) and those receiving placebo (58 of 407 [14.3\%]); the absolute difference was -2.4 percentage points ( $95 \%$ confidence interval, -7.0 to $2.2 ; \mathrm{P}=0.35$ )(11) Our study findings were different from those reported by Sun Hee Lee et al who reported that post-exposure hydroxychloroquine prophylaxis was completed in 184 (97.4\%) patients and 21 (95.5\%) care workers without serious adverse events.(12) At the end of 14 days of quarantine, follow-up PCR tests were all negative. Contrary to our study were findings of Chatterjee $\mathrm{P}$ et al who observed that consumption of four or more maintenance doses of HCQ was associated with a significant decline in the odds of getting infected (AOR: 0.44; 95\% Cl: 0.22-0.88); a dose-response relationship existed between frequency of exposure to $\mathrm{HCQ}$ and such reductions ( $\chi 2$ for trend=48.88; $\mathrm{P}<0.001)$. (13) Although we found that higher number of nurses $(40.6 \%)$, followed by interns (27.1\%), Junior Resident doctors (11.8\%) came out to be COVID19 test positive, as compared to Senior Resident Doctors (8.4\%), Faculty consultants and Administrative staff (each 5\%) were COVID19 infected. This could be due to higher risk of exposure as nurses, interns and Junior resident Doctors are more involved in the patient care as compared to Senior Doctors and faculties serving as Consultants. We found that chances of the getting COVID19 infection decreases as one is posted at Covid area (42.3\%), followed by general patient care $(30.5 \%)$ to Non Covid area $(23.7 \%)$ and the association was found to be statistically significant ( $p$ value- 0.03 ) Therefore, shuffling the duties of health care workers from higher exposure zone to lower exposure zone will reduce the chance of COVID19 infection.

\section{Conclusion}

We therefore found that Hydroxychloroquine prophylaxis does not prevent Covid 19 infection among health care workers and more evidence may be required for use of HCQ prophylaxis for COVID19 infection.

\section{Recommendation}

As COVID19 is new pandemic and very less information is available this disease. With high transmission rate, still social distancing, wearing of mask and regular hand washing will be best preventive measures till any other prophylactic medicine is available for this disease.

\section{Limitation of the study}

Due to high morbidity and mortality of COVID19 offline study couldn't be done. Fluidity of ever-changing guidelines hindered from having a Prospective cohort study.

\section{Relevance of the study}

As potential mechanism of action of Hydroxychloroquine on SARS-CoV1 and SARS-CoV2 is not fully known, its unnecessary use as prophylactic drug for this disease will serve no purpose.

\section{Authors Contribution}

All author contributed equally.

\section{References}

1. Martini M, Gazzaniga V, Bragazzi NL, Barberis I. The Spanish Influenza Pandemic: a lesson from history 100 years after 1918. J Prev Med Hyg. 2019;60(1):E64-E67. Published 2019 Mar 29. doi:10.15167/2421-4248/jpmh2019.60.1.1205

2. Coronavirus disease (COVID-19) Situation Report - 113 Data as received by WHO from national authorities, 27 Aug 2020 [cited on 28 Aug 2020] Available from: https://www.who.int/docs/defaultsource/coronaviruse/situation-reports/2020809-covid-19-sitrep202.pdf?sfvrsn=feac3b6d_2

3. Liu Y, Gayle AA, Wilder-Smith A, Rocklöv J. The reproductive number of COVID-19 is higher compared to SARS corona virus. J Travel Med. 2020; 27(2):taaa021.

4. Ingraham NE, Boulware D, Sparks MA, et al. Shining a light on the evidence for hydroxychloroquine in SARS-CoV-2. Crit Care. 2020; 24(1):182.

5. National Taskforce for COVID-19. Advisory on the use of hydroxychloroquine as prophylaxis for SARS-CoV-2 infection. 2020. https://www.mohfw.gov.in/pdf/AdvisoryontheuseofHydroxychlor oquinasprophylaxisforSARSCoV2infection.pdf (accessed on 25.06.2021).

6. Revised advisory on the use of Hydroxychloroquine (HCQ) as prophylaxis for COVID-19 infection (in supersession of previous advisory dated 23rd March, 2020). https://www.mohfw.gov.in/pdf/RevisedAdvisoryontheuseofHydr oxychloroquinasprophylaxisforSARSCoV2infection. (accessed on Jun 25, 2021).

7. Tahiri Joutei Hassani R, Bennis A. Hydroxychloroquine as antiviral prophylaxis for exposed caregivers to Covid-19: An urgent appraisal is needed. J Infect Public Health. 2020;13(6):865-867. doi:10.1016/j.jiph.2020.05.005

8. Yao $\mathrm{X}, \mathrm{Ye} \mathrm{F}$, Zhang $\mathrm{M}$, et al. In vitro antiviral activity and projection of optimized dosing design of hydroxychloroquine for the 
INDIAN JOURNAL OF COMMUNITY HEALTH / VOL 33 / ISSUE NO 02 / APR- JUN 2021 treatment of severe acute respiratory syndrome Coronavirus 2 (SARS- CoV-2). Clin Infect Dis. 2020:ciaa237.

9. Liu J, Cao R, Xu M, et al. Hydroxychloroquine, a less toxic derivative of chloroquine, is effective in inhibiting SARS-CoV-2 infection in vitro. Cell Discov. 2020; 6:1-4.

10. Wang $\mathrm{M}$, Cao $\mathrm{R}$, Zhang $\mathrm{L}$, et al. Remdesivir and chloroquine effectively inhibit the recently emerged novel coronavirus (2019nCoV) in vitro. Cell Res. 2020; 30:269-271.

11. Boulware DR, Pullen MF, Bangdiwala AS, et al. A Randomized Trial of Hydroxychloroquine as Post exposure Prophylaxis for Covid-19
[A retrospective cohort...] | Mathur NN et al [published online ahead of print, 2020 Jun 3]. N Engl J Med. 2020; NEJMoa2016638. doi:10.1056/NEJMoa201663

12. Sun Hee Lee, Hyunjin Son, Kyong Ran Peck. Can post-exposure prophylaxis for COVID-19 be considered as one of outbreak response strategies in long-term care hospitals? International Journal of Antimicrobial Agents (2020), doi: https://doi.org/10.1016/j.ijantimicag.2020.105988

13. Chatterjee et al: HCQ prophylaxis in HCW in India. Indian J Med Res 2020, Epub ahead of print DOI: 10.4103/ijmr.IJMR 2234 20

\section{Tables}

\section{TABLE 1 DISTRIBUTION OF STUDY SUBJECTS ACCORDING TO SOCIODEMOGRAPHIC PROFILE ( $\mathrm{N}=527$ )}

\begin{tabular}{|c|c|c|c|}
\hline Age group & Male(\%) & Female(\%) & Total(\%) \\
\hline 21 to 30 years & $69(30.0)$ & $161(70.0)$ & $230(43.6)$ \\
\hline 31 to 40 years & $51(34.7)$ & $96(65.3)$ & $147(27.9)$ \\
\hline 41 to 50 years & $19(21.8)$ & $68(78.2)$ & $87(16.5)$ \\
\hline 51 to 60 years & $18(32.7)$ & $37(67.3)$ & $55(10.4)$ \\
\hline 61 to 70 years & $2(25.0)$ & $6(75.0)$ & $8(1.5)$ \\
\hline \multicolumn{4}{|c|}{ Health Care worker type } \\
\hline Intern & $0(0.0)$ & $100(100.0)$ & 89(16.9) \\
\hline Junior Resident Doctor & $33(41.3)$ & $47(58.7)$ & $80(15.2)$ \\
\hline Senior Resident Doctor & $25(40.3)$ & $37(59.7)$ & $62(11.8)$ \\
\hline Faculty & $54(41.5)$ & $76(58.5)$ & $130(24.7)$ \\
\hline Nurse & 28(19.6) & $115(80.4)$ & 143(27.1) \\
\hline Technician & $7(70.0)$ & $3(30.0)$ & 10(1.9) \\
\hline AdministrativeClerical Staff/ & 10(90.9) & $1(9.1)$ & $11(2.1)$ \\
\hline Sanitary workers & $2(100.0)$ & $0(0.0)$ & $2(0.4)$ \\
\hline \multicolumn{4}{|c|}{ Posting of health care worker } \\
\hline Covid area & $62(34.4)$ & $118(65.6)$ & $180(34.2)$ \\
\hline General OPD/Ward/OT & $45(26.6)$ & $124(73.4)$ & 169(32.1) \\
\hline Non Covid Area & $29(26.1)$ & $82(73.9)$ & $111(21.1)$ \\
\hline Both Covid and Non Covid Area & $23(34.3)$ & $44(65.7)$ & $67(12.7)$ \\
\hline \multicolumn{4}{|c|}{ Posting in Covid area in weeks } \\
\hline Not Posted & $62(30.1)$ & 144(69.9) & 206(39.1) \\
\hline Posted for 1 week & $19(26.0)$ & $54(74.0)$ & 73(13.9) \\
\hline Posted for 2 weeks & $24(21.1)$ & $90(78.9)$ & $114(21.6)$ \\
\hline Posted for 3 weeks & $19(33.3)$ & $38(66.7)$ & $57(10.8)$ \\
\hline Posted for 4 or more weeks & $35(45.5)$ & $42(54.5)$ & $77(14.6)$ \\
\hline Total & $159(30.2)$ & $368(69.8)$ & $527(100.0)$ \\
\hline
\end{tabular}

\section{TABLE 2 DISTRIBUTION OF STUDY SUBJECTS AS PER HCQ PROPHYLAXIS AND COVID19 TEST}

\begin{tabular}{|lrrr|}
\hline HCQ (N=527) & & Frequency & Percentage \\
\hline Drug taken & & 229 & 43.5 \\
\hline Drug Not taken & HCQ drug taken continuously (n=229) & 298 & 56.5 \\
\hline & & & 79.5 \\
\hline Yes & HCQ dose skipped (n=229) & 181 & 20.5 \\
\hline No & & 47 & 63.8 \\
\hline & & 145 & 18.3 \\
\hline Never & & 42 & 9.6 \\
\hline Once & & 22 & 2.1 \\
\hline Few times & HCQ course $\mathbf{( n = 2 2 9 ) *}$ & 5 & 6.5 \\
\hline Almost always & & 15 & 54.6 \\
\hline Don't Remember & & 125 & \\
\hline
\end{tabular}




\section{Covid 19 Test $(\mathrm{N}=527)$}

Positive 59

Negative 182

Doubtful

5

Refused for testing

281

281

TABLE 3 ASSOCIATION OF HCQ PROPHYLAXIS AND COVID 19 TEST RESULTS

\begin{tabular}{|c|c|c|c|}
\hline & Covid 19 Positive (\%) n=59 & $\begin{array}{r}\text { Covid } 19 \text { Negative(\%) } \\
n=182\end{array}$ & \\
\hline HCQ taken & $22(21.2)$ & $82(78.8)$ & \multirow{2}{*}{$\begin{array}{l}\text { Relative risk }=0.709 \\
\mathrm{Cl}(0.383-1.296) \\
\mathrm{P} \text { value- }>0.05\end{array}$} \\
\hline HCQ Not taken & $37(27.0)$ & $100(73.0)$ & \\
\hline \multicolumn{4}{|c|}{ HCQ prophylaxis course among those who took the drug and Covid19 test $(n=104)$} \\
\hline Full Course & $9(14.8)$ & $52(85.2)$ & \multirow[t]{3}{*}{$P$ value $<0.05$} \\
\hline Partial Course & $11(42.3)$ & $15(57.7)$ & \\
\hline Were still taking the drug & $2(11.8)$ & $15(88.2)$ & \\
\hline
\end{tabular}

TABLE 4 ASSOCIATION OF POSTING OF STUDY SUBJECTS IN COVID AREA AND COVID 19 TEST RESULTS

\begin{tabular}{|lrr|}
\hline Area in which posted & Covid 19 Positive & Covid 19 Negative \\
\hline Covid area & $25(42.3 \%)$ & $72(39.5 \%)$ \\
\hline General OPD/OT/Ward & $18(30.5 \%)$ & $59(32.4 \%)$ \\
\hline Non Covid Area & $14(23.7 \%)$ & $23(12.6 \%)$ \\
\hline Both Covid and Non Covid area & $2(3.3 \%)$ & $28(15.3 \%)$ \\
\hline Total & & 182 \\
\hline$\chi^{2}-\mathbf{8 . 5 8}$ df- $\mathbf{3} \quad$ p value $\mathbf{0 . 0 3 1}$ & & \\
\hline
\end{tabular}

\section{Figure}

FIGURE 1 THE SAMPLING FLOW OF THE STUDY

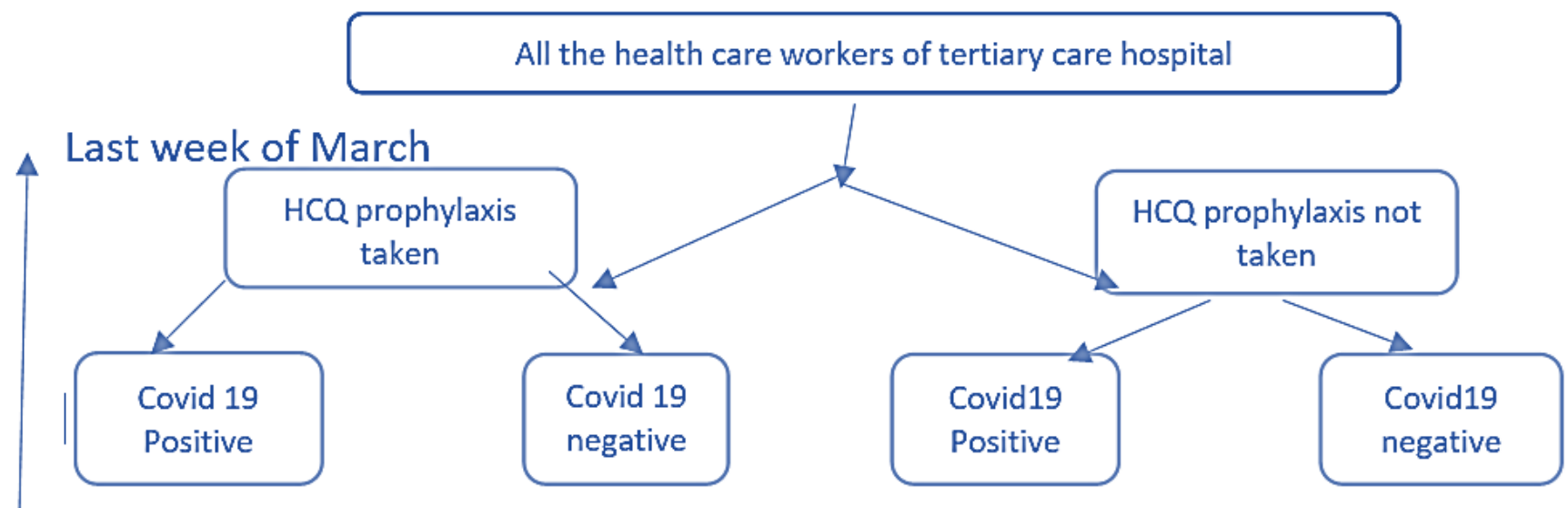

1 Jun to 27 July 2020 